\title{
Influence of clinical context on interpretation and use of an advance care planning policy: a qualitative study
}

\author{
Marta Shaw PhD, Shelley Raffin Bouchal RN PhD, Lauren Hutchison RN MSc, Reanne Booker RN MSc, \\ Jayna Holroyd-Leduc MD, Deborah White RN PhD, Andrew Grant MD, Jessica Simon MD
}

\section{Abstract}

Background: Advance care planning is a process through which people share their values, goals and preferences regarding future medical treatments with the purpose of aligning care received with patient wishes. The objective of this study was to explore perspectives from patients and clinicians in 4 clinical settings to understand how context influences interpretation and application of advance care planning processes.

Methods: This study used a qualitative interpretive descriptive design. Patient and clinician participants were recruited across 4 clinical outpatient settings (cancer, heart failure, renal failure and supportive living) in Calgary and Edmonton. Data were collected between 2014 and 2015 by means of recorded one-on-one semistructured interviews. We analyzed the data using thematic analysis in 2016-2017.

Results: Thirty-four patients and 34 clinicians participated in interviews. Themes common to all 4 contexts were lack of shared understanding between patients and clinicians, and a lack of consistent clinical process related to advance care planning. Advance care planning understanding and process varied substantially between contexts. This variation seemed to be driven by differences in perceptions around disease burden and the nature of the physician-patient relationship.

Interpretation: Provision of a system-wide policy and procedural framework alone was not found to be sufficient to form a standardized approach to advance care planning, as considerable variability existed in advance care planning process between and within clinical settings. Quality-improvement methods that consider local processes, gaps and barriers can help in developing a consistent, comprehensive process.

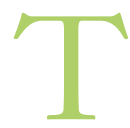
here is growing demand for person-centred care that reflects the wishes of patients. ${ }^{1}$ All those with capacity can consent to or decline medical interventions; however, seriously ill people may not be capable of making or communicating their decisions. ${ }^{2}$ Advance care planning is a process that supports adults at any age or stage of health in sharing their values, goals and preferences regarding future medical care. ${ }^{3}$ To improve concordance between patient wishes and provided care, health care systems across Canada are engaged in efforts to increase the frequency and quality of advance care planning.

Rates of advance care planning engagement and concordance between patient wishes and care provided remain low in Canada. ${ }^{4-6}$ Various patient and clinician factors affect the uptake of advance care planning, ${ }^{7}$ including findings from work by this research team in the supportive living setting exploring patient and health care provider readiness to engage in advance care planning. ${ }^{8}$ Different clinical contexts can also uniquely influence the attitudes, approaches and processes of advance care planning. ${ }^{9-11}$ These differences have not been examined within a single study in 1 health region that operates under the same system-wide policy and procedure. This is important because it is difficult to gain a robust understanding of the factors influencing uptake of advance care planning among clinical contexts if these are compared across varying health regions, each with unique advance care planning policies and priorities. Furthermore, advance care planning interventions that have been successful tend to target advance care

Competing interests: Jessica Simon is a physician consultant, Advance Care Planning and Goals of Care, Alberta Health Services, Calgary Zone. From 2014 to 2019, she had grant support from Alberta Innovates, the Canadian Institutes of Health Research, the Canadian Frailty Network and Alberta Health. Jayna Holroyd-Leduc is an associate editor for CMAJ Open and was not involved in the editorial decision-making process for this article. No other competing interests were declared.

This article has been peer reviewed.

Correspondence to: Marta Shaw, marta.shaw@ucalgary.ca

CMAJ Open 2020. DOI:10.9778/cmajo.20190100 
planning processes. ${ }^{12}$ Thus, understanding factors that uniquely affect the process of advance care planning across clinical contexts can inform targeted interventions.

Starting in 2008, Alberta Health Services began implementing a policy and procedure for advance care planning, and a framework for communicating health care decisions and medical orders called Goals of Care Designations. The policy provides broad recommendations and emphasizes early initiation of conversations, with a focus on patient wishes and goals for treatment, within appropriate therapeutic options. Implementation of advance care planning was accompanied by the building of infrastructure (website, patient resources, standardized Goals of Care Designation and conversation tracking record) and education via provider e-module and seminars.

The objective of this study was to compare patient and clinician perceptions from 4 clinical settings (contexts): cancer, chronic disease (heart and renal failure) and elder care (residents of supportive living facilities). We aimed to understand how clinical context may influence interpretation and uptake of existing advance care planning policy and procedure.

\section{Methods}

\section{Design}

We applied a qualitative interpretive descriptive design to gain an understanding of advance care planning process between and among the 4 contexts and how this process is shaped. ${ }^{13}$ Interpretive descriptive design is a noncategoric qualitative research methodology that aims to generate knowledge pertaining to a practice question of inquiry. It is well suited to the aim of this study as it promotes the creation of knowledge for the purpose of informed action.

\section{Participants}

Patients were eligible if they were aged 18 years or more, spoke English, had no cognitive impairment and had 1 or more of the following conditions: congestive heart failure, cancer (leukemia or lymphoma), chronic renal failure or residing in supportive living. ${ }^{14}$ Exclusion criteria included lack of capacity to consent. Patients were invited to participate in the study by nurse managers. Clinicians were eligible for participation if they were employed within 1 of the clinical contexts under study. They were recruited by means of snowball sampling. ${ }^{15}$

\section{Setting}

Edmonton and Calgary are the largest 2 cities in the western Canadian province of Alberta. Participants were enrolled between April 2014 and June 2015 from 4 outpatient settings: 4 supportive living facilities in Calgary, 1 heart function outpatient clinic in Calgary and 1 in Edmonton, 1 cancer outpatient clinic in Calgary and 1 in Edmonton, and 1 renal clinic in Calgary. These patients are at risk for both chronic and acute deterioration of their condition, frequent hospital admissions and death. ${ }^{16-19}$ Thus, these settings have been identified as priority areas for advance care planning by the provincial health system ${ }^{20}$ and are important end users of data regarding advance care planning.

\section{Data collection}

Patients were interviewed in the clinic or supportive living facility. Clinicians were interviewed in their location of choice. We used one-on-one semistructured interviews with guides $^{8}$ addressing broad questions about the advance care planning process, individual roles, barriers and facilitators (Appendix 1, available at www.cmajopen.ca/content/8/1/E9/ suppl/DC1). We developed the interview guides after a review of the literature, exploring stages of change theory in relation to advance care planning. ${ }^{8,21}$

Four trained interviewers (including M.S., L.H. and R.B.) conducted all interviews, with a single interviewer assigned to each setting. Interviews lasted between 20 minutes and 1 hour. Interviews were audiorecorded, transcribed verbatim and uploaded to the Health and Research Data Repository, a secure virtual research environment at the University of Alberta. Field notes made by the interviewers captured additional observations, such as characteristics of the participants' setting and any hearing or comprehension problems. Interviews continued until saturation of data on advance care planning perspectives was reached, as determined by regular meetings among the interviewers.

\section{Data analysis}

Coded data were entered into the computer software NVivo (QSR International) (M.S., L.H., R.B.). In accordance with the flexibility of interpretive descriptive design, we performed a thematic analysis. ${ }^{22} \mathrm{We}$ analyzed the data for each setting separately by 1) immersion in the data during data collection, during which the interviewers listened to each interview, read transcripts and made notes to gain a familiarity with overarching messages; 2) coding by each interviewer with guidance and scrutiny from content and methodological experts (J.S., S.R.B.); and 3) development of a subtheme template by grouping codes and refining patterns through a constant comparative method. Emerging patterns between groupings were challenged, reviewed and revised. ${ }^{23}$

Next, the research team, including a palliative care doctor (J.S.), a nursing researcher ( $\mathrm{PhD})$ (S.R.B.), a health services research doctoral student (M.S.) and 2 nursing master's students (L.H., R.B.), met over the course of 2016-2017 to analyze the data, with comparison across all 4 clinical contexts, by familiarization with the data through review of notes, codes and groupings; amalgamation of subtheme templates through refinement via assessment of similarities/differences and patterns; and development of final themes (Appendix 2, available at www.cmajopen.ca/content/8/1/E9/suppl/DC1), performed inductively from the analysis.

We did not use an a priori coding tree; rather, data informed the themes. The guiding goal was to describe the advance care planning process among and between contexts, and to gain an understanding of the factors that influence that process. Through reflection, debate and comparison, we used subthemes to develop a hierarchical system of overarching (i.e., conversation drivers) and more narrow (i.e., patient-clinician relationship) themes. The researchers were focused on addressing the stated analytic goal while also being receptive to any interview information that might alter or expand the purpose. 


\section{Ethics approval}

This study was approved by the University of Calgary Conjoint Research Ethics Board. Written informed consent was obtained from each participant.

\section{Results}

In total, 66 interviews were conducted with 34 clinicians and 34 patients (Table 1). Two themes emerged common to all 4 contexts: lack of shared understanding between patients and clinicians, and lack of consistent clinical process related to advance care planning. Understanding of advance care planning and the advance care planning process varied between contexts, driven by disease burden and the nature of the clinician-patient relationship.

\section{Lack of shared understanding of advance care planning}

Patients and clinicians expressed varying conceptualizations of advance care planning (Table 2). This was often not a term familiar to patients, and many associated advance care planning exclusively with the completion of related end-of-life activities, such as transitioning to nonindependent living and completing a will. Some patients felt that advance care planning was synonymous with planning the next medical intervention. When asked directly about specific activities, patients exhibited a thoughtful approach to key advance care planning steps (thinking, discussing, documenting).

In contrast, clinicians across all contexts expressed a complex understanding of advance care planning as a process by which to elicit values and preferences for future health care, particularly in life-threatening conditions, and to communicate prognosis. Still, there was concern among clinicians that a greater emphasis was sometimes placed on completion of medical order forms (Goals of Care Designations) than on conversations and elucidation of values.

\section{Lack of common advance care planning process and uncertainty around roles}

When advance care planning was considered to be a multidisciplinary activity, role challenges were particularly apparent (Table 2). In the heart failure context, advance care planning was often nurse led, but communication between physicians and nurses was not standardized, and physicians were sometimes unsure about how the process functioned. In supportive living, nonphysician clinicians were conflicted, knowing that they had a responsibility in the advance care planning process but uncertain about its extent. In the renal failure context, advance care planning tasks were inconsistently passed among clinical staff, physicians, a dedicated advance care planning nurse or palliative care consultants. For example, 1 nursing staff member indicated that she annually alerted the physician to update Goals of Care Designations forms and discussions, whereas physicians stated that they referred patients to the advance care planning nurse or palliative care consultants.

These various approaches are not mutually exclusive but indicate a lack of consistency in the initiation of advance care planning. In the cancer setting, advance care planning appeared to be primarily, if not exclusively, the responsibility of physicians, some of whom embraced it whereas others expressed unease.

\section{Conversation drivers}

The nature and timing of advance care planning conversations appeared to be driven by 2 related considerations that varied between contexts and clinician role: clinicians' perception of disease burden, and the relationship between clinicians and patients (Table 2).

\section{Disease burden}

Physician perceptions of disease burden emerged as a major driving force in advance care planning conversations, including

\begin{tabular}{|c|c|c|c|c|c|}
\hline \multirow[b]{2}{*}{ Group } & \multicolumn{5}{|c|}{ Role; no. of participants* } \\
\hline & Total & $\begin{array}{l}\text { Nursing } \\
\text { specialties }\end{array}$ & $\begin{array}{l}\text { Social } \\
\text { worker }\end{array}$ & Dietitian & Physician \\
\hline \multicolumn{6}{|l|}{ Clinicians } \\
\hline Supportive living & 9 & 5 & 1 & 0 & 3 \\
\hline Heart function outpatient clinic & 9 & 2 & 0 & 1 & 6 \\
\hline Renal outpatient clinic & 8 & 3 & 1 & 0 & 4 \\
\hline Cancer outpatient clinic & 8 & 3 & 1 & 0 & 4 \\
\hline Patients & & Male/female sex & $\begin{array}{c}\text { Age range, } \\
y r\end{array}$ & & \\
\hline Supportive living & 10 & $0 / 10$ & $72-92$ & - & - \\
\hline Heart function outpatient clinic & 8 & $3 / 5$ & $65-82$ & - & - \\
\hline Renal outpatient clinic & 10 & $5 / 5$ & $66-88$ & - & - \\
\hline Cancer outpatient clinic & 6 & $4 / 2$ & $40-59$ & - & - \\
\hline
\end{tabular}


Table 2 (part 1 of 2): Quotes illustrating themes

\begin{tabular}{|c|c|}
\hline Theme & Representative quote \\
\hline \multicolumn{2}{|c|}{ Variable understanding of advance care planning } \\
\hline \multirow[t]{7}{*}{ Patients } & $\begin{array}{l}\text { I think it [advance care planning] just means ... where you go and what you do when you get to the point } \\
\text { where you can't look after yourself. (supportive living patient 2) }\end{array}$ \\
\hline & Oh yeah, my will's all done. (heart function clinic patient 1 ) \\
\hline & Yeah, we have done that ... we have our funeral arrangements all made. (supportive living patient 3 ) \\
\hline & $\begin{array}{l}\text { We've gone through the process of arranging our, what do they call it, the finances and I believe the health } \\
\text { issues if we're unable to make decisions. (renal failure clinic patient } 7 \text { ) }\end{array}$ \\
\hline & $\begin{array}{l}\text { You could say that the ... bone marrow transplant was care planning because the... Rituxan [rituximab] didn't } \\
\text { work, so we're looking to plan for the next. ... And then after that, we planned for the next event because we } \\
\text { knew it's [lymphoma] going to come back or we assumed it would come back, so we got into bendamustine. } \\
\text { (cancer clinic patient 2) }\end{array}$ \\
\hline & $\begin{array}{l}\text { First of all ... you'd have to be afraid of dying in order to do a whole bunch of the advance planning. I'm not } \\
\text { scared to die ... I don't want to live in a bed or a wheelchair ... so if that's called advance planning, then that's as } \\
\text { far as I've ever gone because I just don't want to be a burden to anybody else. (heart function clinic patient 5) }\end{array}$ \\
\hline & $\begin{array}{l}\text { We spent a lot of time thinking about what we wanted. This isn't something you can just sign, you have to } \\
\text { really think about it. (supportive living patient } 8 \text { ) }\end{array}$ \\
\hline \multirow[t]{4}{*}{ Clinicians } & $\begin{array}{l}\text { Originally, I thought it was something that got you right to the resources, but now I understand it's a way of } \\
\text { thinking, a way of managing, a way of preparing family and the patient to think about what they want to do for } \\
\text { the next stage of their life. (heart function clinic dietitian) }\end{array}$ \\
\hline & $\begin{array}{l}\text { It's our obligation ... to keep people informed about what may happen to them in the future ... how they can } \\
\text { participate and decide what happens to them. (heart function clinic physician } 1 \text { ) }\end{array}$ \\
\hline & $\begin{array}{l}\text { Often they [physicians] would push the Goals of Care [Designation] sheet across to the family and say "Do you } \\
\text { want them left where they are right now, or should we put them at another level?" And ... I'm not in charge of } \\
\text { that whole process, but it's kind of like "Let's just take a step back for a minute, and let's talk about what } \\
\text { changes maybe you've seen in the last year." (supportive living nurse 3) }\end{array}$ \\
\hline & $\begin{array}{l}\text { The situation where I work, I think it's more ... starting a conversation ... about patients' wishes ... both the } \\
\text { patient and the family ... with the ultimate goal at least to put something on paper. (cancer clinic physician } 1 \text { ) }\end{array}$ \\
\hline \multicolumn{2}{|c|}{ Inconsistent process and role uncertainty } \\
\hline \multirow[t]{2}{*}{ Heart function clinic } & $\begin{array}{l}\text { I know that ... the heart failure clinics are very structured. So nursing, I'm certain ... approaches patients about } \\
\text { that [advance care planning] early on in their interactions with them.... Whether that happens on the first } \\
\text { encounter, we're not sure. (physician } 2 \text { ) }\end{array}$ \\
\hline & $\begin{array}{l}\text { Usually it's the nurse who brings it up. Sometimes it's the physician. It depends on the situation but it's } \\
\text { definitely not a conversation that we do on a regular basis. (physician 5) }\end{array}$ \\
\hline \multirow[t]{2}{*}{ Cancer clinic } & $\begin{array}{l}\text { It's just like anything else. ... "Do you have an allergy? Are you on any medications? What are your goals ... } \\
\text { what do you want us to achieve here?" (physician 3) }\end{array}$ \\
\hline & $\begin{array}{l}\text { As the physician, it's my responsibility. I hate it - I absolutely hate it, especially if I don't know the person. } \\
\text { (physician 4) }\end{array}$ \\
\hline \multirow[t]{2}{*}{ Supportive living } & They [nurses] don't know whether — how far they should go, what they should do. (nurse 1) \\
\hline & I really think that the multidisciplinary team don't know ... there's this huge role. (nurse 2) \\
\hline Renal failure clinic & $\begin{array}{l}\text { We make sure that once a year, like when ... the patient comes in to see the nephrologist, that the goals of } \\
\text { care are up to date and if [the patient is] not ... letting the nephrologist know, so then that nephrologist can } \\
\text { have that conversation with the patient. (nurse 1) }\end{array}$ \\
\hline
\end{tabular}

the subjective assessment of the impact of disease on the patient's function and quality of life, expected degree of benefit from treatments and expected trajectory of illness. Physicians' beliefs regarding when a disease had become "burdensome" appeared to determine when conversations were initiated, which, in turn, established the purpose of advance care planning conversations.

Illness complexity and fluctuation factored into the advance care planning approach for the heart failure, renal failure and cancer contexts in ways specific to the context. In the heart failure setting, ongoing and practically focused advance care planning was pursued in expectation of the fluc- tuation inherent in patients' decline. Advance care planning conversations determined treatments and interventions throughout the course of illness or health decline to optimize patients' quality of life as related to physical functioning. In the cancer setting, the possibility of cure appeared to hinder physicians from engaging in advance care planning, which was reserved for a deterioration in the patient's health status, usually associated with treatment failure. Similarly, in the renal failure setting, advance care planning was triggered by substantial health decline and, therefore, focused on end-of-life planning. In the supportive living context, initiation of advance care planning conversations was driven by clinicians' 
Table 2 (part 2 of 2): Quotes illustrating themes

\begin{tabular}{|c|c|}
\hline Theme & Representative quote \\
\hline \multirow[t]{16}{*}{ Disease burden } & We have an advance care planning nurse, so we kind of let her do her thing. (renal failure clinic physician 2) \\
\hline & $\begin{array}{l}\text { The challenge with chronic conditions, especially in cardiac, is the trajectory of their illness is unknown, and } \\
\text { it's up and down and up and down, so there may ... be points where they're feeling ... "These are my } \\
\text { wishes'”... and then the course of their illness changes, so their idea of what they want to continue on with } \\
\text { changes.... But that's where it becomes really important ... that you're having those conversations on more } \\
\text { than } 1 \text { occasion. (heart function clinic physician 1) }\end{array}$ \\
\hline & I don’t mind talking about it. I know l'm going to die. Sooner or later. (heart function clinic patient 5) \\
\hline & $\begin{array}{l}\text { We have to talk to people about their prognosis ... in part because we can modify it by giving them drug } \\
\text { therapies or device therapies ... and some of those therapies also have a benefit in terms of how people feel, } \\
\text { and some of them don't. So it automatically generates a discussion about whether that's a value to them. } \\
\text { (heart function clinic physician } 6 \text { ) }\end{array}$ \\
\hline & $\begin{array}{l}\text { I guess I want to be in control of my life ... and if I have to rely on somebody else to feed me and dress me } \\
\text { and take me to the toilet, I don't want that. I refuse.... That's quality of life. (heart function clinic patient } 9 \text { ) }\end{array}$ \\
\hline & $\begin{array}{l}\text { Unfortunately, we get asked when we're in the midst of being acutely ill. And therefore, you're not equipped to } \\
\text { come up with those answers as easily as you would've if you were feeling well. (cancer clinic patient 4) }\end{array}$ \\
\hline & $\begin{array}{l}\text { There's a certain threshold that you cross, and once you cross that threshold, that's when these conversations } \\
\text { happen more easily, right? (cancer clinic patient 5) }\end{array}$ \\
\hline & $\begin{array}{l}\text { My practice is mostly lymphoma, so there might be patients who I meet the first time in the ... consultation ... [to } \\
\text { whom] l'd say "Okay, look, you have a very aggressive lymphoma. I'm not sure this [transplant] is going to work. } \\
\text { We're going to try this going in, but at some point, if things aren't working, we're going to have a different discussion." } \\
\text {... So for some patients it's really obvious I can do that, and then [for] others, it's a pretty straightforward thing ... "No, } \\
\text { no, we're still heading into cure" and I don't have to talk about the negatives. (cancer clinic physician 1) }\end{array}$ \\
\hline & $\begin{array}{l}\text { Probably if the doctor ... brought it [advance care planning] up as something that ... I need to look into. Like, } \\
\text { having the doctor's ... encouragement would make ... the process easier. (cancer clinic patient } 6 \text { ) }\end{array}$ \\
\hline & $\begin{array}{l}\text { The medical community does note when patients are declining, and I have been asking other roles to consult } \\
\text { to changing the goals of care when patients are declining. (renal failure clinic nurse } 1 \text { ) }\end{array}$ \\
\hline & $\begin{array}{l}\text { If I feel like } \ldots \text { I don't see very good prognosis } \ldots \text { that death is to happen in a very near future } \ldots \text { then I } \\
\text { absolutely need to bring up earlier. (renal failure clinic physician } 1 \text { ) }\end{array}$ \\
\hline & $\begin{array}{l}\text { [Advance care planning is] something that was never really thought about. ... I'm still pretty much on the } \\
\text { healthy side. Although I have kidney failure and I have to take the dialysis. (renal failure clinic patient } 1 \text { ) }\end{array}$ \\
\hline & $\begin{array}{l}\text { The bigger philosophical question is whether or not ... life is worth living at that point, and that ... becomes } \\
\text { very hard, especially with dementia. (supportive living physician 1) }\end{array}$ \\
\hline & $\begin{array}{l}\text { I tend to be less fatalistic ... with some families who are saying "C1 [level of care] ... has got dementia, "Not } \\
\text { the man he used to be," "Wouldn't want to live like this," "We promised he wouldn't go to a nursing home" and } \\
\ldots \text {. I look at him and I say "Well, he's attending programming, and he's eating full meals, and he still recognizes } \\
\text { his family." (supportive living physician 2) }\end{array}$ \\
\hline & $\begin{array}{l}\text { When you get to } 90 \text { and } \ldots \text { you don't have the best of health and }-\ldots \text { I wouldn't put my family through that.... } \\
\text { So we did talk about it, and they all agreed at the end. (supportive living patient } 10 \text { ) }\end{array}$ \\
\hline & $\begin{array}{l}\text { I think once you're starting to see more frailty and more contact with the system ... probably then is the time.... If } \\
\text { it's been awkward up until this point ... you know, if you're over } 75 \text { and you've been in the hospital twice in the } \\
\text { last year ... if you haven't had the conversation, you probably should. (supportive living physician 1) }\end{array}$ \\
\hline \multicolumn{2}{|c|}{ Relationships as conversation drivers } \\
\hline \multirow[t]{2}{*}{ Heart function clinic } & $\begin{array}{l}\text { I don't offer them a carte blanche ... . Usually, I tell them about the disease ... different ways of dying ... and ... } \\
\text { options ... but I wouldn't discuss transplantation in someone who's } 80 \text { years old and has renal failure ....so I } \\
\text { don't offer options that are not really available for that patient. (physician 1) }\end{array}$ \\
\hline & $\begin{array}{l}\text { I would say ... "Do you know about this program, and it could maybe ease your family and yourself ... reduce } \\
\text { the stressors ... if you can plan ahead as to how you would want things done." (nurse 2) }\end{array}$ \\
\hline \multirow[t]{3}{*}{ Supportive living } & You have to draw people out through your relationship and understand their values. (social worker 1) \\
\hline & $\begin{array}{l}\text { I don't do it on the first "Hello, how are you?" I like to develop rapport with patients before introducing the topic } \\
\text { [advance care planning]. (physician 3) }\end{array}$ \\
\hline & $\begin{array}{l}\text { I think it can be a little ... with the goals of care ... although it's always intended to be "This is the patient's } \\
\text { wish, this needs to be respected throughout the sector" ... sometimes it's not necessarily the patient's wish, } \\
\text { but there's a bullishness to how it's ... become dogmatic, "This is an M1" or "This is a C1." (nurse 5) }\end{array}$ \\
\hline Renal failure clinic & $\begin{array}{l}\text { I'm going to continue to bring it up at every single meeting until we get this document [Goals of Care } \\
\text { Designation] because this is just really important for us to know. (physician 3) }\end{array}$ \\
\hline \multirow[t]{2}{*}{ Cancer clinic } & $\begin{array}{l}\text { I don't really give them [patients] a choice. I just tell them "Okay, this is what's happening. I think if something } \\
\text { drastic happens to you - like if you have a cardiac arrest or something serious happens - because of your } \\
\text { disease and how terminal it is, my recommendation is that we don't do resuscitation." (physician 2) }\end{array}$ \\
\hline & My approach is often to suggest to patients ... what they should want in this situation. (physician 3 ) \\
\hline
\end{tabular}


perception of patients' physical functioning and frailty, and the purpose of advance care planning was to develop treatment plans based on patients' current state. Physicians found determination of quality of life to be difficult owing to the high prevalence of dementia.

Patients with heart failure were willing to have conversations about advance care planning early. Patients with cancer were receptive to advance care planning and felt that deteriorating health status lent itself well to initiation of this topic, although some highlighted the problematic nature of initiating conversations during an acute medical event. Unlike in the other contexts, there was striking agreement between patients and clinicians in the renal failure setting, with both opting to leave advance care planning discussions until a time when patients were acutely ill and in substantial health decline. The considerations of patients in supportive living for medical intervention were prioritized based on prospects for physical independence, quality of life and family considerations rather than the physical functioning that drove health care providers to broach advance care planning.

\section{Patient-clinician relationship}

The relationship between patient and clinician was a second important conversation driver (Table 2). Clinicians valued building rapport before engaging in advance care planning discussions, but professional role influenced the content of conversations. Allied health care professionals tended to emphasize the importance of providing support and understanding patients' values. Conversely, many physicians described taking a directive role in the relationship, focusing on the specifics of illness, and treatment options or availability.

\section{Interpretation}

Our findings show there were few instances in which clinicians and patients were congruent in their understanding and conceptualization of advance care planning. The advance care planning process was inconsistent within and between settings, compounded by some providers' uncertainty about their role in the process. Conversations were driven by clinicians' perceptions around progression of disease and the relationship between providers and patients. These perceptions, in turn, determined the timing and content of advance care planning conversations. Although attitudinal similarities were found within each setting, initiation of advance care planning was largely provider dependent, which highlights the lack of an explicit and routinized process to engage patients.

A system-wide policy and procedural framework does not appear sufficient to form a standardized early approach to advance care planning, as we identified considerable variability in specific clinical considerations that affect and determine advance care planning. Our study adds to the literature by identifying clinicians' perception of disease burden as a key determinant of the timing and content of advance care planning.

The process of advance care planning has not been studied widely. ${ }^{12}$ As was found in the current study, patients, particu- larly as they age, are willing to engage, but their knowledge of advance care planning remains limited. ${ }^{8,24}$ Our findings suggest that uncertainty regarding illness course and clinician beliefs around appropriate treatments affect the timing of advance care planning conversations. Similarly, prior research showed that physician uncertainty related to illness trajectory, prognosis, clinician roles and lack of a routinized advance care planning process in clinical settings are barriers to implementation efforts aimed at increasing advance care planning. . $^{12,25,26}$ These factors can prevent appropriate timing of advance care planning. ${ }^{12}$ Advance care planning has been shown to be delayed until the very end of life for both patients with cancer and those undergoing hemodialysis. ${ }^{27}$ This is especially problematic, as patients may receive limited benefit from care services such as hospice care.

Exploration of the advance care planning process across clinical settings highlights the opportunity for intervention studies aimed at establishing an appropriate and clinically relevant process to reduce practice variability and optimize advance care planning. Quality-improvement methods applied at both the micro- and macrosystem level that consider local processes, gaps and barriers can help in developing a consistent, comprehensive process. ${ }^{28}$ It may be feasible to engage clinical teams in simple quality-improvement exercises in order to establish current advance care planning practice and ideal practice, and to determine changes and role clarifications necessary to fill the gaps between the two.

Reducing variation in contextual processes cannot be done through written procedure alone. Adopting simple conversation guides and tools can help clinicians expand the focus of advance care planning conversations to better encompass patient values and quality-of-life considerations. ${ }^{29}$ The Serious Illness Conversation Program can assist clinicians in framing discussions to elicit patient values, ${ }^{30}$ as training physicians in communication around advance care planning has been shown to improve engagement. ${ }^{30}$ The Respecting Choices program is an example of a facilitator-led process. ${ }^{31}$ Such programs can be adapted to the disease context.

\section{Limitations}

The potential representativeness of perspectives in this study was limited by inclusion of English-speaking participants only, our cancer population included only patients with hematologic disorders, and the patients were identified by nurse managers and thus may not be fully representative of patients in each clinical context. Our finding that advance care planning is driven by clinician perceptions of disease burden suggests that, in making this determination, patient input is not necessarily sought. We did not explore whether patient perception of disease burden also influences how older adults relate to advance care planning, but this has been confirmed by prior work. 2,7

\section{Conclusion}

Considerable variability existed in advance care planning process between and within clinical settings. As a result, health care providers' perceptions of context-specific considerations 
drive the timing and content of advance care planning discussions. A focus on routinizing advance care planning may help to decrease practice variability and ensure timely and ongoing advance care planning across clinical settings.

\section{References}

1. Cook D, Rocker G, Heyland D. Enhancing the quality of end-of-life care in Canada. CMA7 2013;185:1383-4

2. Simon J, Porterfield P, Bouchal SR, et al. 'Not yet' and 'Just ask': barriers and facilitators to advance care planning - a qualitative descriptive study of the perspectives of seriously ill, older patients and their families. BMF Support Palliat Care 2015;5:54-62.

3. Sudore RL, Lum HD, You JJ, et al. Defining advance care planning for adults: a consensus definition from a multidisciplinary Delphi panel. 7 Pain Symptom Manage 2017;53:821-32.e1.

4. Heyland D, Dodek P, Lamontagne F. Advance care planning evaluation in hospitalised elderly patients: a multicenter, prospective study (The ACCEPT Study). BM7 Support Palliat Care 2012;2:195.

5. Heyland DK, Barwich D, Pichora D, et al. Failure to engage hospitalized elderly patients and their families in advance care planning. FAMA Intern Med 2013;173:778-87

6. Heyland DK, Heyland R, Dodek P, et al. Discordance between patients' stated values and treatment preferences for end-of-life care: results of a multicentre survey. BM7 Support Palliat Care 2017;7:292.

7. Lovell A, Yates P. Advance care planning in palliative care: a systematic literature review of the contextual factors influencing its uptake 2008-2012. Palliat Med 2014;28:1026-35.

8. Shaw M, Hewson J, Hogan DB, et al. Characterizing readiness for advance care planning from the perspective of residents, families, and clinicians: an interpretive descriptive study in supportive living. Gerontologist 2018;58:739-48.

9. Beattie JM, Flynn TN, Davidson PM. Fifty shades of dying: the challenge of advance care planning across the spectrum of disease trajectories in advanced heart failure. BM7 Support Palliat Care 2013;3:247.

10. Dow LA, Matsuyama RK, Ramakrishnan V, et al. Paradoxes in advance care planning: the complex relationship of oncology patients, their physicians, and advance medical directives. 7 Clin Oncol 2010;28:299-304.

11. O'Hare AM, Szarka J, McFarland LV, et al. Provider perspectives on advance care planning for patients with kidney disease: Whose job is it anyway? Clin 7 Am Soc Nephrol 2016;11:855-66.

12. Lund S, Richardson A, May C. Barriers to advance care planning at the end of life: an explanatory systematic review of implementation studies. PLoS One 2015;10:e0116629.

13. Thorne SE. Interpretive description. Walnut Creek (CA): Left Coast Press; 2008:272.

14. Turnquist K. Supportive living, sustainable care. Minn Med 2015;98:36-7.

15. Noy C. Sampling knowledge: the hermeneutics of snowball sampling in qualitative research. Int 7 Soc Res Methodol 2008;11:327-44.

16. Poppe M, Burleigh S, Banerjee S. Qualitative evaluation of advanced care planning in early dementia (ACP-ED). PLoS One 2013;8:e60412.

17. Davison SN. End-of-life care preferences and needs: perceptions of patients with chronic kidney disease. Clin 7 Am Soc Nephrol 2010;5:195-204.

18. Denvir MA, Murray SA, Boyd KJ. Future care planning: a first step to palliative care for all patients with advanced heart disease. Heart 2015;101:1002-7.
19. De Vleminck A, Pardon K, Beernaert K, et al. Barriers to advance care planning in cancer, heart failure and dementia patients: a focus group study on general practitioners' views and experiences. PloS One 2014;9:e84905.

20. Implementation guide to advance care planning in Canada: a case study of two health authorities. Ottawa: Health Canada; 2008: Available: https:/www. canada.ca/en/health-canada/services/health-care-system/reports-publications/ palliative-care/implementation-guide-advance-care-planning-canada-case-study -two-health-authorities-2008.html (accessed 2019 Dec. 16).

21. Fried TR, Redding CA, Robbins ML, et al. Promoting advance care planning as health behavior change: development of scales to assess decisional balance, medical and religious beliefs, and processes of change. Patient Educ Couns 2012; $86: 25-32$

22. Thorne SE. Interpretive description: qualitative research for applied practice, second edition. Oxford (UK): Routledge; 2016.

23. Braun V, Clarke V. What can "thematic analysis" offer health and wellbeing researchers? Int 7 Qual Stud Health Well-being 2014;9:26152.

24. Porensky EK, Carpenter BD. Knowledge and perceptions in advance care planning. 7 Aging Health 2008;20:89-106.

25. Bernacki RE, Block SD; American College of Physicians High Value Care Task Force. Communication about serious illness care goals: a review and synthesis of best practices. FAMA Intern Med 2014;174:1994-2003.

26. Johnson M, Janssen D. Advance care planning: A 'hard' skill for cardiology clinicians? Heart 2019;105:1298-99.

27. Ferrell BR. Late referrals to palliative care. 7 Clin Oncol 2005;23:2588-9.

28. Plsek PE, Wilson T. Complexity, leadership, and management in healthcare organisations. BM7 2001;323:746-9.

29. Butler M, Ratner E, McCreedy E, et al. Decision aids for advance care planning: an overview of the state of the science. Ann Intern Med 2014;161:408-18.

30. Bernacki R, Hutchings M, Vick J, et al. Development of the Serious Illness Care Program: a randomised controlled trial of a palliative care communication intervention. BM7 Open 2015;5:e009032.

31. Pecanac KE, Repenshek MF, Tennenbaum D, et al. Respecting Choices ${ }^{\circledR}$ and advance directives in a diverse community. 7 Palliat Med 2014;17:282-7.

Affiliations: Cumming School of Medicine (Shaw, Grant), University of Calgary; Community Health Sciences (Holroyd-Leduc, Simon), University of Calgary; Faculty of Nursing (Raffin Bouchal, Hutchison, Booker, White), University of Calgary, Calgary, Alta.

Contributors: Jessica Simon, Shelley Raffin Bouchal, Lauren Hutchison and Marta Shaw conceptualized and designed the project. Lauren Hutchison, Reanne Booker and Marta Shaw acquired the data. Jessica Simon, Jayna Holroyd-Leduc, Shelley Raffin Bouchal, Lauren Hutchison, Reanne Booker, Deborah White and Marta Shaw analyzed and interpreted the data. Marta Shaw drafted the manuscript, with assistance from Jessica Simon, Jayna Holroyd-Leduc, Shelley Raffin Bouchal, Reanne Booker, Lauren Hutchison, Andrew Grant and Deborah White. Jessica Simon, Jayna Holroyd-Leduc, Deborah White and Andrew Grant revised the manuscript critically for important intellectual content. All of the authors approved the final version to be published and agreed to be accountable for all aspects of the work.

Supplemental information: For reviewer comments and the original submission of this manuscript, please see www.cmajopen.ca/content/8/1/ E9/suppl/DC1. 